\title{
Substance use disorders in military veterans: prevalence and treatment challenges
}

This article was published in the following Dove Press journal:

Substance Abuse and Rehabilitation

30 August 2017

Number of times this article has been viewed

\author{
Jenni B Teeters ${ }^{1,2}$ \\ Cynthia L Lancaster ${ }^{1,2}$ \\ Delisa G Brown ${ }^{3}$ \\ Sudie E Back ${ }^{1,2}$ \\ 'Department of Psychiatry and \\ Behavioral Sciences, Medical \\ University of South Carolina, \\ Charleston, SC, USA; ${ }^{2}$ Ralph $\mathrm{H}$ \\ Johnson Veterans Affairs (VA) \\ Medical Center, Charleston, SC, USA, \\ ${ }^{3}$ Department of Human Development \\ and Psychoeducation, Howard \\ University, Washington, DC, USA
}

Correspondence: Jenni B Teeters Psychological Sciences Department, Western Kentucky University, 3040 Gary Ransdell Hall, Bowling Green, KY 42I0I, USA

Tel + I 2707452439

Email jenni.teeters@wku.edu

Sudie E Back

Department of Psychiatry and Behavioral Sciences, Medical University of South Carolina, 5 Charleston Center Drive, Suite I5I, Charleston, SC 29407, USA

Tel + I 8437929383

Email backs@musc.edu

\begin{abstract}
Substance use disorders (SUDs) are a significant problem among our nation's military veterans. In the following overview, we provide information on the prevalence of SUDs among military veterans, clinical characteristics of SUDs, options for screening and evidence-based treatment, as well as relevant treatment challenges. Among psychotherapeutic approaches, behavioral interventions for the management of SUDs typically involve short-term, cognitive-behavioral therapy interventions. These interventions focus on the identification and modification of maladaptive thoughts and behaviors associated with increased craving, use, or relapse to substances. Additionally, client-centered motivational interviewing approaches focus on increasing motivation to engage in treatment and reduce substance use. A variety of pharmacotherapies have received some support in the management of SUDs, primarily to help with the reduction of craving or withdrawal symptoms. Currently approved medications as well as treatment challenges are discussed.
\end{abstract}

Keywords: addiction, alcohol use disorders, drug use disorders, treatment, pharmacotherapy, psychotherapy

\section{Introduction}

Substance use disorders (SUDs) are a significant problem among military veterans and are associated with numerous deleterious effects. ${ }^{1-3}$ There are a number of services and interventions available to help reduce SUDs among veterans, including both behavioral and pharmacological treatments. The aims of this review are to provide information on the epidemiology of SUDs among military veterans, clinical characteristics of SUDs, and options for screening and treatment. Challenges and barriers to treatment are also discussed. For the purposes of this review, the focus is primarily on veterans who previously served in the military (i.e., are now retired or separated from the military). Additionally, much of the available research on SUDs among military veterans focuses on Department of Veterans Affairs (VA) services and patients. Notably, some of the features of VA care, such as integration and relatively easy access to specialty mental health care and/or treatment for SUDs, which are discussed in this review, may not be present in non-VA treatment settings.

Despite numerous attempts by the VA and other agencies over the past two decades to reduce problematic substance use, rates of SUDs in veterans continue to rise. SUDs are associated with substantial negative correlates, including medical problems, other psychiatric disorders (e.g., depression and anxiety), interpersonal and vocational impairment, and increased rates of suicidal ideation and attempts. ${ }^{2,4}$ 
One study of military personnel found that $\sim 30 \%$ of completed suicides were preceded by alcohol or drug use, and an estimated $20 \%$ of high-risk behavior deaths were attributed to alcohol or drug overdose. ${ }^{5,6}$ Given the deleterious associations with SUDs, greater attention to the identification of effective, evidence-based treatment is critically needed. In this paper, we review the prevalence of SUDs among veterans as well as options for treatment. Articles selected for inclusion in this overview were chosen following an extensive literature search in PubMed using relevant key words (e.g., military substance use disorders, veteran substance use disorders, and veteran addiction). Preference for inclusion was given to articles published in the past 10 years.

\section{Diagnostic criteria}

SUDs are defined in the Fifth Edition of the Diagnostic and Statistical Manual of Mental Disorders $(D S M-5)^{7}$ as a pattern of use that results in marked distress and/or impairment, with two or more symptoms occurring in the past year (see Box 1 for DSM-5 diagnostic criteria). The DSM-5 marked the transition of SUD from a categorical model of severity (previously defined as "abuse" or "dependence") to a more dimensional model in which SUDs are qualified as mild, moderate, or severe, based on the number of symptoms endorsed by the patient. ${ }^{7}$

\section{Prevalence rates}

Prior to presenting epidemiological data, it is important to note that many VA-based studies published prior to the release of DSM-5 in May 2013 used The International Classification of Diseases, Ninth Revision (ICD-9) diagnosis codes (which roughly correspond to the $D S M-4$ criteria). Differences in diagnostic criteria may lead to some important differences in rates of SUDs among those utilizing VA care. For example, previous studies have concluded that prevalence rates of SUDs differ based on the specific criteria used, with studies using diagnostic criteria (i.e., DSM) reporting higher rates of SUDs when compared to studies using administrative data (i.e., ICD-9). ${ }^{8}$ Additionally, because not all veterans choose to utilize VA health care services and only a percentage of patients receive mental health care through the VA and receive a diagnosis, VA diagnostic rates may not reflect true prevalence rates, even among VA patients. Furthermore, studies presenting data solely from veterans that utilize the VA do not capture substance use rates among all military veterans and may have a selection bias, as not all veterans receive care through VA hospitals. ${ }^{9}$

The most prevalent types of substance use problems among male and female veterans include heavy episodic drinking and cigarette smoking. ${ }^{9}$ Among veterans presenting for first-time care within the VA health care system, $\sim 11 \%$ meet criteria for a diagnosis of SUD. ${ }^{3}$ Consistent with the general population, alcohol and drug use disorder diagnoses are more common among male than female veterans (10.5\% current alcohol use disorders and $4.8 \%$ current drug use disorders among male veterans; $4.8 \%$ current alcohol use disorders and $2.4 \%$ current drug use disorders among female veterans) and are more common among non-married and younger veterans (i.e., $<25$ years old). ${ }^{3}$ Demographics associated with higher rates of SUDs (e.g., young, male) in the general civilian population make up a greater proportion of the military population, which could contribute to an increased risk of certain SUDs relative to civilians. ${ }^{2,3,10} \mathrm{~A}$ number of environmental stressors specific to military personnel have been linked to increased risk of the development of SUDs among military personnel and veterans, including deployment, combat exposure, and post-deployment civilian/ reintegration challenges. ${ }^{3,11}$ Onset of SUDs can also emerge secondary to other mental health problems associated with

Box I DSM-5 diagnostic criteria for substance use disorders

Substance use disorders are defined as a pattern of use that results in marked distress and/or impairment, with two or more of the following symptoms over the course of a 12-month period:

I. Using the substance in larger amounts or over a longer period of time than intended

2. Unsuccessful attempts or persistent desire to reduce use

3. Too much time spent on obtaining, using, and/or recovering from the effects of the substance

4. A strong craving for the substance

5. Significant interference with roles at work, school, or home

6. Continued use despite recurrent social or interpersonal consequences

7. Reducing or giving up important social, occupational, or recreational activities because of the substance use

8. Substance use in situations in which it may be physically hazardous

9. Substance use despite recurrent or persistent physical or psychological consequences

10. Tolerance of the substance

II. Withdrawal from the substance

Note: Adapted from American Psychiatric Association. Diagnostic and Statistical Manual of Mental Disorders (DSM-5 $\left.{ }^{\circledR}\right)$. Washington, DC: American Psychiatric Publishing; 20I 3. ${ }^{7}$ 
these stressors, such as post-traumatic stress disorder (PTSD) and depression. ${ }^{12,13}$ Additionally, interpersonal traumas (e.g., histories of child physical or sexual abuse) have been shown to mediate the risk of developing an SUD among military veterans, and some individuals join the military to escape adverse home environments. ${ }^{14,15}$ Furthermore, age is an important predictor of SUD prevalence, with higher rates of SUDs associated with younger age. It is important to keep in mind that many estimates lump together all age groups despite significant variation by age. For example, a recent epidemiological study found that among male veterans, the overall prevalence of substance abuse was lower than rates of civilian substance use when all ages were examined together. ${ }^{9}$ However, when looking at the pattern for male veterans aged 18-25 years only, the rates of substance abuse were higher in veterans compared with civilians.

\section{Specific substances}

Despite strict US military policies implemented in 1986 to reduce problematic alcohol consumption, heavy drinking and alcohol use disorders are common among military personnel. ${ }^{2,16}$ Policies tend to be enforced with inconsistency, and heavy alcohol consumption has long been a cultural norm used for recreation, stress relief, and socializing among military personnel. ${ }^{1,2}$ Alcohol use disorders are the most prevalent form of SUD among military personnel. ${ }^{3,17}$ A study examining data collected as part of the National Survey on Drug Use and Health found that, compared to their non-veteran counterparts, veterans were more likely to use alcohol (56.6\% vs $50.8 \%$ in a 1 -month period), and to report heavy use of alcohol ( $7.5 \%$ vs $6.5 \%$ in a 1 -month period) ${ }^{18}$ Furthermore, negative consequences from alcohol use (e.g., interpersonal, legal, and professional) are about twice as likely among binge drinkers relative to non-binge drinkers ( $9 \%$ vs $4 \%$ ), and among heavy drinkers relative to binge drinkers ( $9 \%$ vs $19 \%) .{ }^{19}$ High levels of combat exposure confer greater risk of problematic alcohol use; those with high levels of combat exposure are more likely to engage in heavy (26.8\%) and binge $(54.8 \%)$ drinking relative to other military personnel (17\% and $45 \%$, respectively). ${ }^{19}$ These increasing rates of problematic drinking are particularly concerning, given that alcohol is the fourth leading cause of preventable death in the general US population, and that alcohol-impaired driving accounts for $31 \%$ of all driving-related fatalities. ${ }^{20,21}$ Among veterans, specifically, studies demonstrate that alcohol use increases risk of interpersonal violence, poorer health, and mortality. ${ }^{22,23}$
Misuse of prescription drugs, such as opioids, is on the rise among veterans. ${ }^{16}$ Opioids, which are one of the most addicting prescription drugs available, ${ }^{25}$ are being prescribed at increasing rates to veterans to address issues such as migraine headaches and chronic pain. ${ }^{26}$ From 2001 to 2009, the percent of veterans in the VA health care system receiving an opioid prescription increased from $17 \%$ to $24 \%$, and the number of prescriptions written for pain medication by military physicians has more than quadrupled. ${ }^{27,28}$ From 2003 to 2007, chronic opioid use (i.e., 6 months or longer) among young veterans in the VA health care system increased from $3.0 \%$ to $4.5 \%{ }^{29}$ On average, patients were prescribed two different opioids and had three different prescribers. ${ }^{29}$ Of these opioid prescriptions, the majority were for oxycodone $(46.9 \%)$, hydrocodone $(39.5 \%)$, or codeine $(6.8 \%) .{ }^{30}$ Mental health diagnoses increase the likelihood of receiving an opioid prescription. Specifically, veterans with a diagnosis of PTSD (17.8\%) or another mental health disorder (11.7\%) were more likely to receive an opioid prescription than those without mental health diagnoses $(6.5 \%) .{ }^{31}$ As compared to veterans without a mental health diagnosis, those with a diagnosis of PTSD receive higher doses of opioid medications, are more likely to receive a simultaneous prescription for additional opioids or for a sedative hypnotic, and are more likely to receive an early refill. ${ }^{31}$ Unfortunately, research suggests that those with mental health disorders are also more likely to develop opioid use disorders and to experience a number of adverse clinical outcomes (e.g., inpatient or emergency room admissions, opioid-related accidents and overdoses, and violence-related injuries). ${ }^{27,31}$

Illicit drug use among veterans is roughly equivalent to their civilian counterparts (4\% in the past month reporting use of any illicit drug). ${ }^{18}$ Marijuana accounts for the vast majority of illicit drug use among veterans $3.5 \%$ report marijuana use, $1.7 \%$ report use of illicit drugs other than marijuana in a 1-month period). ${ }^{18}$ From 2002 to 2009, cannabis use disorders increased $>50 \%$ among veterans in the VA health care system. ${ }^{32}$ Finally, data suggest that veterans are more likely to be smokers, and age-adjusted prevalence of smoking is higher among veterans than matched civilian groups (27\% vs $21 \%) .{ }^{33}$ Of concern for medical outcomes, more veterans than civilians with coronary heart disease are smokers. ${ }^{33}$ Furthermore, cigarette smoking accounts for $23 \%$ of cancer-related deaths among veterans who are former smokers, and 50\% of cancer-related deaths among current smokers. ${ }^{34}$ 


\section{Treatments}

There are a number of services and interventions available to help reduce SUDs among veterans. These include both behavioral and pharmacological treatments, and range on a spectrum from preventive screening to residential treatment programs. SUD treatment services are available to veterans connected with VA Medical Centers (VAMC) across the country. However, many veterans are not connected with a local VAMC and even when they are, access to care can be challenging. This is especially true for rural veterans who may not have a qualified provider in the area (see "Treatment challenges" section for more discussion on these issues). ${ }^{35}$

The sections below focus on psychotherapies and pharmacotherapies typically utilized to treat SUDs among veterans. In addition to these behavioral and pharmacological interventions reviewed below, however, veterans with SUDs are encouraged to try self-help groups, such as Alcoholics Anonymous (AA) and Narcotics Anonymous (NA), which are free of charge and available in most cities. Participation in AA/NA can be particularly helpful as part of "aftercare" and ongoing engagement with services to help manage SUDs. Providers are encouraged to consult the recently updated VA/Department of Defense Clinical Practice Guidelines for SUDs for more detailed treatment recommendations. ${ }^{81}$

\section{Psychotherapy}

In response to high rates of alcohol use among veterans, the VA has implemented system-wide alcohol screening. The goal of Screening, Brief Intervention, and Referral to Treatment (SBIRT) is to intervene upon risky and unhealthy drinking habits prior to progression to an alcohol use disorder, or to provide immediate treatment to those with alcohol use disorders. ${ }^{24}$ According to the VA/Department of Defense Clinical Practice Guidelines for SUDs, if treatment or further evaluation is indicated and acceptable to a patient after receiving a brief intervention, the patient should be offered a specialty referral or management in primary care. The guidelines state that if there is "an indication for and a willingness to seek treatment" a biopsychosocial assessment should be completed followed by the development and implementation of a comprehensive treatment plan. Following the collaborative development of the treatment plan, SUD-focused pharmacotherapy should be offered, if indicated, for alcohol use disorders and opioid use disorders, and all patients should be offered SUD-focused psychosocial interventions. Evidencebased psychotherapies and behavioral interventions for the management of SUDs typically involve short-term, cognitivebehavioral therapy (CBT) interventions. These interventions focus on the identification and modification of maladaptive thoughts and behaviors associated with increased craving, use, or relapse to substances. In addition, they may help reduce SUDs by helping incentivize individuals to achieve and maintain abstinence (e.g., contingency management therapies), or increase their ability to successfully manage stress without substances. Behavioral interventions can be delivered in person, via telehealth, and/or via the Internet. ${ }^{36-40}$

Client-centered motivational interviewing approaches focus on helping increase motivation to engage in treatment and reduce or abstain from substances. ${ }^{41}$ Walker et al conducted a randomized controlled trial of motivational interviewing among 242 Army personnel. Participants received one session of motivational interviewing plus feedback or a psychoeducation control. The findings showed that the intervention resulted in significantly fewer drinks per week and lower rates of alcohol dependence diagnosis. ${ }^{42}$

Recognizing that young veterans are often unlikely to seek care at traditional VAMCs, researchers have begun to develop alternative, novel methods of treatment engagement and delivery. For example, Pedersen et al developed a web-based, single-session intervention to reduce alcohol use among young veterans. ${ }^{43}$ In just 2 weeks, using Facebook as a recruitment site, they recruited a sample of 784 veterans. The intervention uses personalized normative feedback (PNF) and was found to reduce number of drinks per week as well as binge drinking 1 month later. The advantages of an intervention like this one include the fact that it requires no clinician time or patient travel to a VAMC. In addition, web-based interventions reduce other barriers to care such as stigma.

\section{Pharmacotherapy}

In addition to behavioral interventions, pharmacotherapy can play an important role in the treatment and management of SUDs. ${ }^{44}$ Medications can help reduce withdrawal symptoms which may serve as a trigger or reason for relapse, if untreated. In addition, medications can be helpful in decreasing craving, which is also a potent trigger for increased substance use or relapse following treatment. There are three medications that are approved by the US Food and Drug Administration (FDA) for alcohol use disorders: naltrexone, acamprosate, and disulfiram. Methadone, buprenorphine, naltrexone, and extended-release injectable naltrexone are approved by the FDA for the treatment of opioid use disorders. There are no FDA-approved medications for the treatment of cocaine or marijuana use disorders.

Recently, exploratory use of off-label medications for SUDs has also been the interest of much attention (e.g., 
oxytocin and $\mathrm{N}$-acetylcysteine).$^{45,46}$ Investigators have also begun to explore the use of medications to treat SUDs and commonly co-morbid mental health disorders. Rarely does a veteran present with only an SUD. Oftentimes, veterans with an SUD also have co-occurring psychiatric conditions such as PTSD or depression. Recent studies have investigated several medications to help identify effective pharmacologic interventions for SUD and PTSD. For example, studies have investigated the use of prazosin, topiramate, and $\mathrm{N}$-acetylcysteine with mixed results. ${ }^{47-49}$

\section{Treatment challenges}

\section{Rural locations}

According to the VA Office of Rural Health, there are $~ 3.4$ million rural veterans ( $41 \%$ ) that comprise the total number of veterans enrolled in VA health care system..$^{50}$ Access to care, particularly mental health services, is problematic for veterans residing in rural areas. Increased access to mental health care via telemental health (TMH) modalities may improve quality of life for veterans living in rural areas. ${ }^{51}$ Feasibility and efficacy have been shown in the utilization of TMH in home-based settings and remote locations among veterans and civilian populations. ${ }^{52-56}$ Though literature directly pertaining to the delivery of TMH services for SUDs is limited, the small body of research that specifically investigates substance use TMH treatments has demonstrated favorable results. ${ }^{53,57}$ Frueh et al examined relapse prevention in veterans with alcohol use disorder using telehealth from a remote site to a local clinic. Results showed that abstinence was retained in 13 of 14 treatment completers and there was high participant satisfaction for the services delivered. ${ }^{57}$ It is also worth noting that this study delivered TMH in a group format. Similar findings were demonstrated among veterans receiving individual home-based TMH (HBTMH) services. Veterans living in rural areas who received HBTMH reported that they prefer to receive their mental health treatment using $\mathrm{TMH}$, they would recommend TMH services to other veterans, and they felt safe and less subjected to perceived stigma associated with mental illness, including SUD. ${ }^{54}$

Clinicians have also cited advantages of TMH services for rural veterans including low no-show rates, reduced stigma felt by patients, reduced costs and travel burden, and social connection. ${ }^{58}$ While the benefits of TMH are promising, the delivery of TMH is not without disadvantages. Limitations include issues with connectivity (e.g., slow bandwidth, problems connecting via satellite internet providers, and availability of internet connection in very rural areas), issues regarding how user savvy the clinician and patient are, and confidentiality and privacy issues, though continuous advancements made in telecommunications have lessened the severity of these issues. Specific to SUD treatment, limitations of TMH include reduced ability to identify when a patient is intoxicated (e.g., inability to smell alcohol or other substance) or conduct unplanned drug testing. ${ }^{53}$ Telehealth can play a considerable role in increasing mental health access for veterans residing in rural communities. TMH overcomes geographic, financial, and stigma-related barriers while yielding high patient satisfaction and perceived safety to veterans who would likely not otherwise receive it. Additionally, telehealth could have a transformative impact on the VA health care system and significantly improve quality of life for veterans.

\section{Female veterans}

In recent years, rates of problematic substance use among female veterans have been increasing. ${ }^{38}$ SUD diagnoses among female veterans utilizing VA services have increased by $81 \%$ from 2005 to $2010 . .^{59}$ Some female veterans may feel uncomfortable seeking SUD treatment within the VA. Female veterans may find it difficult to disclose substance use to providers due to perceived stigma and shame associated with being a female substance user. ${ }^{60}$ Additionally, female veterans with SUDs have higher rates of childhood sexual abuse, military sexual trauma, and domestic violence than female veterans without SUDs, and women with PTSD are particularly at risk of developing substance-related problems. ${ }^{61,62}$ SUD treatments are often provided in groups made up primarily of male veterans. ${ }^{62}$ Understandably, female veterans may feel uncomfortable discussing traumatic experiences in a male-dominated treatment setting. Female veterans may also be more likely to have childcare needs that may interfere with treatment utilization and engagement. ${ }^{63} \mathrm{It}$ is important for providers to remain conscious of women's minority status within the military and the VA and to handle hesitancy to disclose with compassion and sensitivity. Female veterans are likely to benefit from specialized SUD treatment and gender-tailored treatment, which may increase treatment utilization, attendance, and comfort. ${ }^{61}$ Female veterans receiving care at VAMCs offering specialized services for women were more likely to engage in treatment and were more receptive to SUD treatment when gender-specific care options were accessible..$^{64,65}$

\section{Dual diagnoses}

Veterans with SUDs commonly meet criteria for co-occurring mental health disorders, such as PTSD, depression, anxiety, 
and adjustment disorder. ${ }^{3}$ Among Operation Enduring Freedom (OEF) and Operation Iraqi Freedom (OIF) veterans diagnosed with an SUD, 82\%-93\% were diagnosed with another comorbid mental health disorder. ${ }^{3}$ Notably, veterans with an SUD diagnosis were three to four times more likely to receive a PTSD or depression diagnosis and $<1 \%$ of veterans received an isolated diagnosis of SUD without any diagnosis of a co-occurring disorder. ${ }^{3}$ Prevalence rates of SUDs and cooccurring disorders among OEF/OIF veterans echo findings from studies on Vietnam-era veterans, although post-Vietnam veterans are more likely to be dually diagnosed. ${ }^{66,67}$ Notably, individuals presenting with multiple diagnoses of SUDs and comorbid disorders demonstrate greater symptom severity and poorer treatment outcomes. ${ }^{17}$ Dually diagnosed veterans are also more likely to have experienced homelessness and to receive VA disability benefits. ${ }^{68}$ Psychiatric symptoms, such as symptoms associated with depression and PTSD, can precede or exacerbate drug and alcohol misuse and psychological distress can increase substance craving. ${ }^{3,69}$ Thus, there is an urgent need for efficacious treatments aimed at treating not only the SUD but also the co-occurring disorder.

Additionally, veterans with SUDs often have co-occurring medical conditions, such as obesity, sleep disturbance, physical injury, and chronic pain as well as other complicating issues such as lower overall quality of life, poorer quality relationships, and higher levels of aggression compared to veterans with a mental health diagnosis but no substance use diagnosis. ${ }^{70-72}$ Female veterans with an SUD diagnosis are more likely to have reproductive and urinary problems than female veterans without an SUD diagnosis while male veterans with an SUD diagnosis are more likely to be diagnosed with circulatory and digestive system diseases than male veterans without an SUD diagnosis. ${ }^{73}$ Though not typically addressed in SUD treatment manuals, these issues are likely to impact treatment and should be addressed during treatment.

Among OEF/OIF veterans, 63\% diagnosed with an SUD also met criteria for PTSD. ${ }^{3}$ Veterans dually diagnosed with PTSD and SUDs are more likely to have additional co-occurring psychiatric and medical conditions, such as seizures, liver disease, HIV, schizophrenia, anxiety disorders, and bipolar disorder. ${ }^{68}$ Due to the high rates of comorbid PTSD and SUDs, the VA has attempted to integrate treatment by funding PTSD/SUD specialist positions and research efforts aimed at identifying efficacious evidence-based PTSD/SUD treatments. ${ }^{74}$ However, services are often underutilized with only about $10 \%$ of SUD positive veterans receiving any type of SUD treatment in the past year. ${ }^{75}$ Though psychotherapy is an important part of treatment for PTSD and SUD, the majority of patients with PTSD and comorbid SUD receive treatment for the SUD only. ${ }^{76,77}$ There remains a prevailing belief that the SUD should be treated first or that a patient must achieve abstinence before beginning treatment, leaving many active substance using clients unable to obtain treatment. ${ }^{77}$ Additionally, patients are not always referred to PTSD treatment after completing SUD treatment. ${ }^{78}$ This may lead to greater likelihood of a relapse in the future due to untreated PTSD symptomology and the chronic nature of addictive disorders. "Integrated" treatment models, in which both the SUD and PTSD are simultaneously addressed in therapy, have been developed over the past decade. The findings from studies of integrated treatments show that substance use typically decreases significantly and does not increase with the addition of trauma-focused interventions. ${ }^{79,80}$ Multiple randomized controlled trials of integrated interventions have been conducted, demonstrating improvements in both PTSD and SUD outcomes. ${ }^{76,79,80}$ However, there is insufficient evidence to conclude that integrated treatments are superior to SUDonly or PTSD-only singular treatments. ${ }^{80}$ Further research is needed to determine whether integrated treatments outperform evidence-based SUD and PTSD treatments. Additionally, research on treatments designed to target other mental health disorders that often co-occur with SUDs, such as depression, anxiety, and adjustment disorders, is greatly needed as the vast majority of veterans with SUDs are dually diagnosed.

\section{Stigma}

Another challenge to treatment that is sometimes encountered by veterans is the stigma associated with seeking SUD treatment. Efforts to integrate SUD care within the context of other mental health care would be helpful. So, instead of having to seek care at the "addiction clinic," veterans could be seen at a general "mental health clinic" that would address a myriad of issues (e.g., anxiety, depression, bereavement, PTSD, couples and family therapy). Furthermore, integrating SUD care into primary care would take it another step further in reducing stigma and increasing access to care. ${ }^{2}$

Additionally, the hypermasculine military culture often places importance and value on self-reliance. Therefore, military veterans may be more likely to strive to solve mental health issues on their own and view getting professional mental health treatment as a sign of "weakness". Additionally, they may feel the need to help "protect" family or friends by not talking about their symptoms or struggles. It is important that providers are aware of these issues so that they can choose to address and normalize these in a sensitive manner early on in treatment. 


\section{Summary}

In summary, veterans demonstrate high rates of SUDs. There is a clear need for the development of novel, more effective, evidence-based interventions to address the health care needs of our veterans and their family members struggling with SUDs. Efforts to overcome barriers to those seeking treatment are needed so that veterans in need of services are able to access treatment and experience long-term recovery.

\section{Acknowledgments}

The authors would like to acknowledge support from National Institute on Drug Abuse grant K02 DA039229 (Back SE) and resources at the Ralph H. Johnson VAMC. The views expressed in this article are those of the authors and do not necessarily reflect the position or policy of NIDA, the Department of Veterans Affairs, or the USA government.

\section{Disclosure}

The authors report no conflicts of interest in this work.

\section{References}

1. Ames GM, Duke MR, Moore RS, Cunradi CB. The impact of occupational culture on drinking behavior of young adults in the US Navy. J Mix Methods Res. 2009;3(2):129-150.

2. Institute of Medicine. Substance Use Disorders in the USArmed Forces. Washington, DC: National Academies Press; 2013.

3. Seal KH, Cohen G, Waldrop A, Cohen BE, Maguen S, Ren L. Substance use disorders in Iraq and Afghanistan veterans in VA healthcare, 2001-2010: implications for screening, diagnosis and treatment. Drug Alcohol Depend. 2011;116(1-3):93-101.

4. Drescher KD, Rosen CS, Burling TA, Foy DW. Causes of death among male veterans who received residential treatment for PTSD. J Trauma Stress. 2003;16(6):535-543.

5. Larson MJ, Wooten NR, Adams RS, Merrick EL. Military combat deployments and substance use: review and future directions. $J$ Soc Work Pract Addict. 2012;12(1):6-27.

6. Dept of the Army; US Army. Army; Health Promotion, Risk Reduction, Suicide Prevention: Report 2010. Available from: http://www. armyg 1.army.mil/hr/suicide/docs/Commanders\%20Tool\%20Kit/ HPRRSP_Report_2010_v00.pdf. Accessed June 22, 2017.

7. American Psychiatric Association. Diagnostic and Statistical Manual of Mental Disorders $\left(D S M-5^{\circledR}\right)$. Washington, DC: American Psychiatric Publishing; 2013.

8. Lan CW, Fiellin DA, Barry DT, et al. The epidemiology of substance use disorders in US Veterans: a systematic review and analysis of assessment methods. Am J Addict. 2016;25(1):7-24.

9. Hoggatt KJ, Lehavot K, Krenek M, Schweizer CA, Simpson T. Prevalence of substance misuse among US veterans in the general population. Am J Addict. 2017;26(4):357-365.

10. Stahre MA, Brewer RD, Fonseca VP, Naimi TS. Binge drinking among US active-duty military personnel. Am J Prev Med. 2009;36(3):208-217.

11. Cerdá M, Richards C, Cohen GH, et al. Civilian stressors associated with alcohol use disorders in the national guard. Am J Prev Med. 2014;47(4):461-466.

12. Polusny MA, Erbes CR, Murdoch M, Arbisi PA, Thuras P, Rath MB. Prospective risk factors for new-onset post-traumatic stress disorder in National Guard soldiers deployed to Iraq. Psychol Med. 2011;41(4): 687-698.
13. Wells TS, LeardMann CA, Fortuna SO, et al. A prospective study of depression following combat deployment in support of the wars in Iraq and Afghanistan. Am J Public Health. 2010;100(1):90-99.

14. Guina J, Nahhas RW, Goldberg AJ, Farnsworth S. PTSD symptom severities, interpersonal traumas, and benzodiazepines are associated with substance-related problems in trauma patients. J Clin Med. 2016;5(8):E70.

15. Blosnich JR, Dichter ME, Cerulli C, Batten SV, Bossarte RM. Disparities in adverse childhood experiences among individuals with a history of military service. JAMA Psychiatry. 2014;71(9):1041-1048.

16. Bray RM, Pemberton MR, Hourani LL, et al. Department of Defense Survey of Health Related Behaviors Among Active Duty Military Personnel: A Component of the Defense Lifestyle Assessment Program (DLAP). Research Triangle Park, NC: Research Triangle Institute; 2009.

17. Kessler RC, Berglund P, Demler O, Jin R, Merikangas KR, Walters EE. Lifetime prevalence and age-of-onset distributions of DSM-IV disorders in the National Comorbidity Survey Replication. Arch Gen Psychiatry. 2005;62(6):593-602.

18. Wagner TH, Harris KM, Federman B, Dai L, Luna Y, Humphreys K. Prevalence of substance use disorders among veterans and comparable nonveterans from the National Survey on Drug Use and Health. Psychol Serv. 2007;4(3):149.

19. Bray RM, Brown JM, Williams J. Trends in binge and heavy drinking, alcohol-related problems, and combat exposure in the US military. Subst Use Misuse. 2013;48(10):799-810.

20. Mokdad AH, Marks JS, Stroup DF, Gerberding JL. Actual causes of death in the United States, 2000. JAMA. 2004;291(10):1238-1245.

21. NHTSA's National Center for Statistics and Analysis; National Highway Traffic Safety Administration; US Department of Transportation. Traffic safety facts: Crash; Stats [2015]. Available from: https://crashstats. nhtsa.dot.gov/Api/Public/ViewPublication/812219. Accessed August 18, 2017.

22. Savarese VW, Suvak MK, King LA, King DW. Relationships among alcohol use, hyperarousal, and marital abuse and violence in Vietnam veterans. J Trauma Stress. 2001;14(4):717-732.

23. Bridevaux IP, Bradley KA, Bryson CL, McDonell MB, Fihn SD. Alcohol screening results in elderly male veterans: association with health status and mortality. JAm Geriatr Soc. 2004;52(9):1510-1517.

24. Babor TF, McRee BG, Kassebaum PA, Grimaldi PL, Ahmed K, Bray J. Screening, Brief Intervention, and Referral to Treatment (SBIRT) toward a public health approach to the management of substance abuse. Subst Abus. 2007;28(3):7-30.

25. Goldman D, Oroszi G, Ducci F. The genetics of addictions: uncovering the genes. Nat Rev Genet. 2005;6(7):521-532.

26. Macey TA, Morasco BJ, Duckart JP, Dobscha SK. Patterns and correlates of prescription opioid use in OEF/OIF veterans with chronic noncancer pain. Pain Med. 2011;12(10):1502-1509.

27. Bohnert AS, Ilgen MA, Trafton JA, et al. Trends and regional variation in opioid overdose mortality among Veterans Health Administration patients, fiscal year 2001 to 2009. Clin J Pain. 2014;30(7):605-612.

28. Morden E, Oster M, O'Brien CP. Substance use disorders in the US Armed Forces. Washington, DC: National Academies Press; 2013.

29. Wu PC, Lang C, Hasson NK, Linder SH, Clark DJ. Opioid use in young veterans. J Opioid Manag. 2009;6(2):133-139.

30. Jeffery DD, May L, Luckey B, Balison BM, Klette KL. Use and abuse of prescribed opioids, central nervous system depressants, and stimulants among US active duty military personnel in FY 2010. Mil Med. 2014;179(10):1141-1148

31. Seal KH, Shi Y, Cohen G, et al. Association of mental health disorders with prescription opioids and high-risk opioid use in US veterans of Iraq and Afghanistan. JAMA. 2012;307(9):940-947.

32. Bonn-Miller MO, Harris AH, Trafton JA. Prevalence of cannabis use disorder diagnoses among veterans in 2002, 2008, and 2009. Psychol Serv. 2012;9(4):404-416.

33. Brown DW. Smoking prevalence among US veterans. J Gen Intern Med. 2010;25(2):147-149. 
34. McLaughlin JK, Hrubsec Z, Blot WJ, Fraumeni JF Jr. Smoking and cancer mortality among US veterans: a 26-year follow-up. Int J Cancer. 1995;60(2):190-193.

35. Santa Ana EJ, Stallings DL, Rounsaville BJ, Martino S. Development of an in-home telehealth program for outpatient veterans with substance use disorders. Psychol Serv. 2013;10(3):304-314.

36. Carroll KM, Onken LS. Behavioral therapies for drug abuse. Am J Psychiatry. 2005;162(8):1452-1460.

37. Carroll KM, Ball SA, Martino S, et al. Computer-assisted delivery of cognitive-behavioral therapy for addiction: a randomized trial of CBT4CBT. Am J Psychiatry. 2008;165(7):881-888.

38. Chapman SL, Wu LT. Suicide and substance use among female veterans: a need for research. Drug Alcohol Depend. 2014;136:1-10.

39. Carroll KM, Easton CJ, Nich C, et al. The use of contingency management and motivational/skills-building therapy to treat young adults with marijuana dependence. J Consult Clin Psychol. 2006;74(5):955-966.

40. Nathan PE, Gorman JM. A Guide to Treatments That Work. New York, NY: Oxford University Press; 2015.

41. Santa Ana EJ, LaRowe SD, Armeson K, Lamb KE, Hartwell K. Impact of group motivational interviewing on enhancing treatment engagement for homeless veterans with nicotine dependence and other substance use disorders: a pilot investigation. Am J Addict. 2016;25(7):533-541.

42. Walker DD, Walton TO, Neighbors $C$, et al. Randomized trial of motivational interviewing plus feedback for soldiers with untreated alcohol abuse. 2016;85(2):99-110.

43. Pedersen E, Parast L, Marshall GN, Schell TL, Neighbors C. A randomized controlled trial of a web-based, personalized normative feedback alcohol intervention for young-adult veterans. $J$ Consult Clin Psychol. 2017;85(5):459-470.

44. Rubinsky AD, Chen C, Batki SL, Williams EC, Harris AH. Comparative utilization of pharmacotherapy for alcohol use disorder and other psychiatric disorders among US Veterans Health Administration patients with dual diagnoses. J Psychiatr Res. 2015;69:150-157.

45. Lee MR, Weerts EM. Oxytocin for the treatment of drug and alcohol use disorders. Behav Pharmacol. 2016;27(8):640-648.

46. Gipson $\mathrm{CD}$. Treating addiction: unraveling the relationship between $\mathrm{N}$-acetylcysteine, glial glutamate transport, and behavior. Biol Psychiatry. 2016;80(3):e11-e12.

47. Back SE, McCauley JL, Korte KJ, et al. A double-blind randomized controlled pilot trial of $\mathrm{N}$-acetylcysteine in veterans with PTSD and substance use disorders. J Clin Psychiatr. 2016;77(11):e1439-e1446.

48. Batki SL, Pennington DL, Lasher B, et al. Topiramate treatment of alcohol use disorder in veterans with posttraumatic stress disorder: a randomized controlled pilot trial. Alcohol Clin Exp Res. 2014;38(8):2169-2177.

49. Petrakis IL, Desai N, Gueorguieva R, et al. Prazosin for veterans with posttraumatic stress disorder and comorbid alcohol dependence: a clinical trial. Alcohol Clin Exp Res. 2016;40(1):178-186.

50. Wong FA; National Veterans Affairs and Rehabilitation Commission. The American Legion; System worth saving program survey. Available from: https://archive.legion.org/bitstream/handle/123456789/1951/ rural_health_veteran_survey.pdf?sequence=3. Accessed June 20, 2017.

51. Wallace AE, Weeks WB, Wang S, Lee AF, Kazis LE. Rural and urban disparities in health-related quality of life among veterans with psychiatric disorders. Psych Serv. 2006;57(6):851-856.

52. Morland LA, Hynes AK, Mackintosh MA, Resick PA, Chard KM. Group cognitive processing therapy delivered to veterans via telehealth: a pilot cohort. J Trauma Stress. 2011;24(4):465-469.

53. Gros DF, Morland LA, Greene CJ, et al. Delivery of evidence-based psychotherapy via video telehealth. J Psychopathol Behav Assess. 2013;35(4):506-521.

54. Shore P, Goranson A, Ward MF, Lu MW. Meeting veterans where they're@: A VA home-based telemental health (HBTMH) pilot program. Int J Psychiatry Med. 2014;48(1):5-17.

55. Pruitt LD, Luxton DD, Shore P. Additional clinical benefits of homebased telemental health treatments. Prof Psychol Res Pract. 2014;45(5): 340-346.
56. Price M, Gros DF. Examination of prior experience with telehealth and comfort with telehealth technology as a moderator of treatment response for PTSD and depression in veterans. Int J Psychiatry Med. 2014;48(1):57-67.

57. Frueh BC, Henderson S, Myrick $\mathrm{H}$. Telehealth service delivery for persons with alcoholism. J Telemed Telecare. 2005;11(7):372-375.

58. Benavides-Vaello S, Strode A, Sheeran BC. Using technology in the delivery of mental health and substance abuse treatment in rural communities: a review. J Behav Health Serv Res. 2013;40(1):111-120.

59. Cucciare MA, Simpson T, Hoggatt KJ, Gifford E, Timko C. Substance use among women veterans: epidemiology to evidence-based treatment. J Addict Dis. 2013;32(2):119-139.

60. Abraham TH, Lewis ET, Drummond KL, Timko C, Cucciare MA. Providers' perceptions of barriers and facilitators to disclosure of alcohol use by women veterans. Prim Health Care Res Dev. 2017;18(1):64-72.

61. Hoggatt KJ, Jamison AL, Lehavot K, Cucciare MA, Timko C, Simpson TL. Alcohol and drug misuse, abuse, and dependence in women veterans. Epidemiol Rev. 2015;37(1):23-37.

62. Suffoletta-Maierle S, Grubaugh AL, Magruder K, Monnier J, Frueh BC. Trauma-related mental health needs and service utilization among female veterans. J Psychiatr Pract. 2003;9(5):367-375.

63. Kimerling R, Pavao J, Greene L, et al. Access to mental health care among women veterans: is VA meeting Women's needs?. Med Care. 2015;53(4 Suppl 1):S97-S104.

64. Oliva EM, Gregor A, Rogers J, Dalton A, Harris AH, Trafton JA. Correlates of specialty substance use disorder treatment among female patients in the Veterans Health Administration. $J$ Soc Work Pract Addict. 2012;12(3):282-301.

65. Lewis ET, Jamison AL, Ghaus S, et al. Receptivity to alcohol-related care among US women Veterans with alcohol misuse. J Addict Dis. 2016;35(4):226-237.

66. Marmar CR, Schlenger W, Henn-Haase C, et al. Course of posttraumatic stress disorder 40 years after the Vietnam War: findings from the National Vietnam Veterans Longitudinal Study. JAMA Psychiatry. 2015;72(9): 875-881.

67. Petrakis IL, Ralevski E, Desai N, et al. Noradrenergic vs serotonergic antidepressant with or without naltrexone for veterans with PTSD and comorbid alcohol dependence. Neuropsychopharmacology. 2012;37(4):996-1004.

68. Bowe A, Rosenheck R. PTSD and substance use disorder among veterans: characteristics, service utilization and pharmacotherapy. $J$ Dual Diagn. 2015;11(1):22-32

69. Sinha R. How does stress lead to risk of alcohol relapse? Alcohol Res. 2012;34(4):432-440.

70. Haibach JP, Haibach MA, Hall KS, et al. Military and veteran health behavior research and practice: challenges and opportunities. J Behav Med. 2017;40(1):175-193.

71. Ralevski E, Gianoli MO, McCarthy E, Petrakis I. Quality of life in veterans with alcohol dependence and co-occurring mental illness. Addict Behav. 2014;39(2):386-391.

72. Owens GP, Held P, Blackburn L, et al. Differences in relationship conflict, attachment, and depression in treatment-seeking veterans with hazardous substance use, PTSD, or PTSD and hazardous substance use. J Interpers Violence. 2014;29(7):1318-1337.

73. Nazarian D, Kimerling R, Frayne SM. Posttraumatic stress disorder, substance use disorders, and medical comorbidity among returning US veterans. J Trauma Stress. 2012;25(2):220-225.

74. Hawkins EJ, Lapham GT, Kivlahan DR, Bradley KA. Recognition and management of alcohol misuse in OEF/OIF and other veterans in the VA: a cross-sectional study. Drug Alcohol Depend. 2010;109(1-3):147-153.

75. Golub A, Vazan P, Bennett AS, Liberty HJ. Unmet need for treatment of substance use disorders and serious psychological distress among veterans: a nationwide analysis using the NSDUH. Mil Med. 2013;178(1):107-114.

76. Najavits LM, Sullivan TP, Schmitz M, Weiss RD, Lee CS. Treatment utilization by women with PTSD and substance dependence. $A m J$ Addict. 2004;13(3):215-224. 
77. Young HE, Rosen CS, Finney JW. A survey of PTSD screening and referral practices in VA addiction treatment programs. J Subst Abuse Treat. 2005;28(4):313-319.

78. McCauley JL, Killeen T, Gros DF, Brady KT, Back SE. Posttraumatic stress disorder and co-occurring substance use disorders: advances in assessment and treatment. Clin Psychol (New York). 2012;19(3):283-304

79. Roberts NP, Roberts PA, Jones N, Bisson JI. Psychological interventions for post-traumatic stress disorder and comorbid substance use disorder: a systematic review and meta-analysis. Clin Psychol Rev. 2015;38:25-38.
80. Torchalla I, Nosen L, Rostam H, Allen P. Integrated treatment programs for individuals with concurrent substance use disorders and trauma experiences: a systematic review and meta-analysis. J Subst Abuse Treat. 2012;42(1):65-77.

81. US Department of Veterans Affairs. VA/DoD Clinical Practice Guidelines. Management of Substance Use Disorder (SUD) (2015). Available from: https://www.healthquality.va.gov/guidelines/MH/sud/. Accessed August 18, 2017.

\section{Publish your work in this journal}

Substance Abuse and Rehabilitation is an international, peer-reviewed, open access journal publishing original research, case reports, editorials, reviews and commentaries on all areas of addiction and substance abuse and options for treatment and rehabilitation. The manuscript management system is completely online and includes a very quick and fair peer-review system. Visit http://www.dovepress.com/testimonials.php to read real quotes from published authors. 